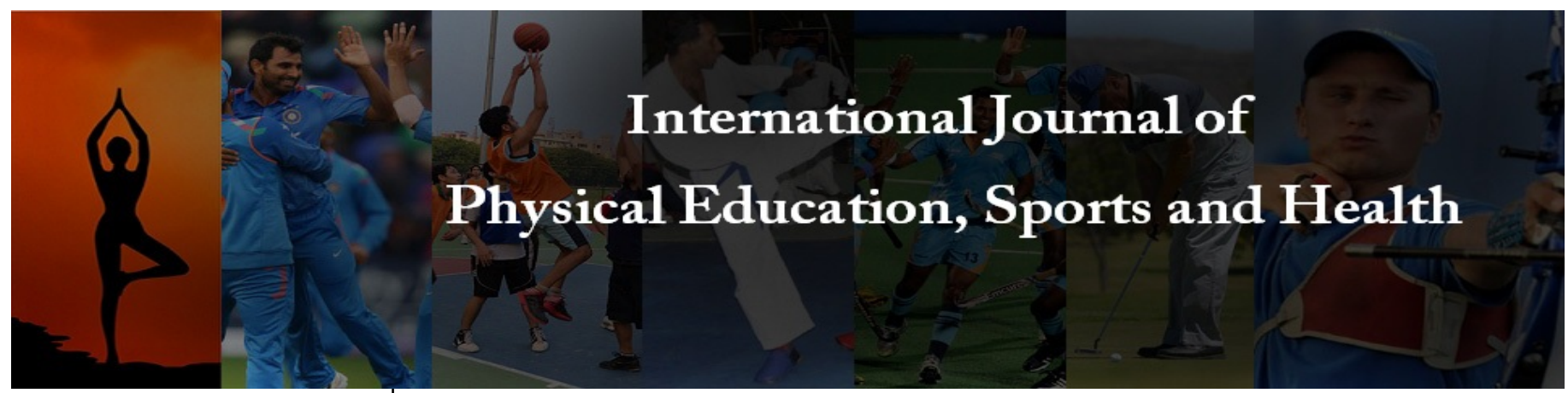

P-ISSN: 2394-1685

E-ISSN: 2394-1693

Impact Factor (ISRA): 5.38

IJPESH 2022; 9(1): 35-43

(C) 2022 IJPESH

www.kheljournal.com

Received: 20-11-2021

Accepted: 22-12-2021

Ramesh Basnet

MPT Student, Rajiv Gandhi

University of Health Sciences,

Oxford College of Physiotherapy

Bangalore, Karnataka, India

Sujan Sukamani

MPT Student, Rajiv Gandhi

University of Health Sciences.

Bangalore, Karnataka, India

Krishna Chandar GU

Assistant Professor, Rajiv Gandhi University of Health

Sciences, Oxford College of

Physiotherapy Bangalore,

Karnataka, India

\section{Study to identify the normative values of left-right discrimination for Indian population aged 20 to 60 years}

\section{Ramesh Basnet, Sujan Sukamani and Krishna Chandar GU}

DOI: https://doi.org/10.22271/kheljournal.2022.v9.i1a.2337

\section{Abstract}

Background: Graded Motor Imagery is a rehabilitation tool to manage pain and improve function. Left right discrimination is one of the component of GMI. People in pain often reduce the ability to identify left and right image of their painful parts. When viewing picture of the body parts they are less slow and less accurate at determining whether the image is left or right than someone without pain.

Objective: The objective of the study is to identify the response time and accuracy in both left and right side of the body by performing the left right discrimination test using the Recognize app for shoulder, hand, knee and foot. And identifying the difference between male and female.

Method: A total of 279 participants were included in the study based on the selection criteria. All the participants completed left right discrimination test for 30 hand image, 30 shoulder image, 30 foot image and 30 knee image in 10 inch tablet tablet using recognize application where accuracy and response time (RT) were noted down.

Outcome Measures: Recognise mobile application version 1.0.6 by Noigroup

Results: The baseline characteristics age and gender wise results was calculated .The normative response time and accuracy for hand image is 2.43 sec with accuracy of $78 \%$. The normative response time and accuracy for shoulder image is $1.90 \mathrm{sec}$ with accuracy of $83.9 \%$. The normative response time and accuracy for foot image is 1.90 sec with accuracy of $87.9 \%$. The normative response time and accuracy for knee image is 2.95 sec with accuracy of $70.5 \%$.

Conclusion: Our study present data in both genders we have found out that in some age category women took longer response time and the accuracy to identifying left right image in less in compared to the men. Overall performance was done and compare with healthy participants. If the further left right discrimination research done on subject with affected body parts this research provide additional data and arguments for maintaining activity in context to pain rehabilitation and self-management.

Keywords: left/right judgment, motor imagery, chronic pain, response time, accuracy

\section{Introduction}

International Association for the Study of Pain (IASP) defined pain as "An unpleasant sensory and emotional experience associated with actual or potential tissue damage." Chronic pain is a common complex problem which is present frequently because of disease and injury. It is not only because of the tissue damage. There are others factors like demographic, lifestyles, behavior, attitude and belief which are associated to the chronic pain. The Global Burden of Disease Study 2016 shows that the pain and pain-related diseases is the leading cause of disability and disease burden. In this world, around 1.9 billion are suffering from chronic pain [1]. Research suggest that chronic pain affects $13-50 \%$ and around $10-14 \%$ were found to have moderate to severe chronic pain ${ }^{[1,2]}$.

Pain is the common reason that most people visit a physiotherapist and other health care personnel. Chronic musculoskeletal pain is one of the most common clinical problems faced by physiotherapist and can be devastating for patients. In order to plan for the treatment of the chronic pain it need to be understood in the context of social, biological, psychological and physical factors ${ }^{[3]}$. Chronic musculoskeletal condition such as osteoarthritis, rheumatoid arthritis, fibromyalgia and low back pain are common cause disability with the significant implication globally.
sCorresponding Author:

Ramesh Basnet

MPT Student, Rajiv Gandhi

University of Health Sciences,

Oxford College of Physiotherapy

Bangalore, Karnataka, India 
Most of these conditions are being treated with high dosage pharmacological analgesics ${ }^{[2,3]}$. Central pain amplification cannot be fully explained on the basis of somatic or neuropathic processes and is due to physiologic alterations in pain transmission or descending pain modulatory pathways. In any individual, central pain amplification may complicate nociceptive or neuropathic pain. Furthermore, patients with somatic symptom disorders may have alterations in their psychological or behavioral responses to pain that contribute significantly to the clinical presentation ${ }^{[4]}$.

Genetic, physiologic, and psychological factors associated with central pain amplification are beginning to be understood. One important contributor to chronic pain is perceived stress and stress response systems. This pain experience will also make competition for central mechanism of consciousness such as attention, information selection, learning avoidance and anticipation.

Central Sensitization is a amplification of neural signaling within the and pain experiences are not always because of tissue damage, they are more in nervous system and brain. Combination of both sensitization and disinhibition on the chronic pain leads systematic change neurons that represent the body $[3,4,5]$.

Research has suggest that painful musculoskeletal condition such as complex regional pain syndrome (CRPS), phantom limb pain, limb pain, osteoarthritis, back pain, carpal tunnel syndrome ${ }^{[6]}$ and focal hand dystonia ${ }^{[7]}$ has altered motor imagery.

Unfortunately, treatments for chronic pain are fully inadequate and often worsen clinical outcomes. Developing new treatment strategies for patients with chronic pain is of utmost urgency.

Graded motor imagery (GMI) is rehabilitation program which is designed to activate cortical motor network and improve cortical organization in three steps: lateral training (left right discrimination), imagined hand movements and mirror visual feedback training ${ }^{[8]}$.

Left right discrimination is process of identifying one side of the body as distinct from the other, or if a body part is rotating to the left or right .Research shows people in pain often lose the ability to identify left or right images of their painful body part(s). That is, when viewing pictures of body parts they are slower and/or less accurate at determining whether the image is a Left or Right than somebody without pain ${ }^{[5]}$.

There are three sequential processes on judging whether a pictured hand or foot belongs to the left or to the right. First, we make an initial spontaneous judgment. This process requires attention to either side of the body, or to either limb, or the processing speed of the CNS. Second, we mentally move our own matching limb in order to mimic the posture of the limb. This requires an intact working body schema and its integration of mental health. Third, we accept or deny the initial judgment. This is dependent on CNS processing speed. If the mental movement does not confirm the initial judgment, the process starts again, which causes a delay ${ }^{[5,9]}$.

Longer reaction times for pictures of one limb relative to the other side probably shows a bias in processing information away from the delayed side or toward the opposite side. Reduced accuracy of left/right judgments shows disruption of the cortical proprioceptive representation (or working body schema) of the body parts so the people on pain often lose the ability to identify left or right images of their painful part ${ }^{[10,}$ 11]

This Left right judgment ability appears to be important for normal recovery from pain. The good news is that the brain is plastic and changeable, if given the right training for long enough. So with the appropriate tools, a bit of work, patience and persistence, it is possible to improve the ability (speed and accuracy) to discriminate between Left and Right body parts and movements ${ }^{[12]}$.

\subsection{Aim of the study:}

This aim of the study is to identify and set the normative response time and accuracy on left right discrimination in Indian population aged between 20 to 60 .

\subsection{Need of Study}

The research shows people suffering from pain have reduce ability to identify right from the left and they are less accurate too. So there is a direct linkage between LRD and level of pain. Most of the individuals stated that they frequently experienced left-right confusion in their daily lives. Some more recent studies estimate the numbers to be even higher [13]. Having a normative data in Indian population will give us benchmark to identify and deviation in the people with chronic pain. And as a treatment adjunct in managing chronic pain LRD normative values will help to monitor change or outcome.

There will be a alters in response time and accuracy of left right discrimination in patient with chronic pain. LRD task is one of the component of Graded Motor Imagery which helps in managing pain.

The normative data we set from our study can be compared with left right discrimination ability that is response time and accuracy on various chronic pain like phantom pain syndrome, Complex Regional Pain Syndrome, low back pain, painful arthritis, neck pains conditions which helps to monitor changes. Further the practice LRD task can active the parts of brain without firing off pain response and can be taken back to normal LRD ability. And this will also add benefits on others GMI therapy like imagined movement, mirror therapy for managing the chronic pain.

Pain is a learned response which may vary because of behavior to the pain, day to day lifestyles and belief towards the pain. So setting a left right discrimination ability data in context to Indian population is necessary.

\section{Materials and Methods \\ 2.1 Methodology}

2.1.1 Source of Data: Participants home, Parasmane Apartments, Amrutha Clinic.

2.1.2 Method of collection of data: The concerned authorities were personally contacted and obtained permission. After obtaining the permission, the participants were screened for meeting the requirements of inclusion criteria and the study was continued.

\subsubsection{Research Design: A Cross-Sectional Design}

2.1.4 Sample Size: 320 participants

2.1.5 Sample size: 320

2.1.6 Sample size estimation is done by

- $\quad$ one sample two sided calculation

- $\quad$ Pilot study done in 20 subject

- Mean and SD deviation calculated from the data of 20 subjects

- $\mathrm{n}=40$ total group 8

- $\quad$ Total sample size $=320$

2.1.7 Sampling Technique: Non probability purposive 
sampling technique.

2.1.8 Duration of Study: 6 month

\subsection{Materials Required:}

- Examination table.

- $\quad$ Tablet with Recognise mobile application version 1.0.6 by Noigroup

- A noise free room

- Consent Form

- Recording sheets.

- Assessment form

- Data collection form

\subsection{Selection Criteria}

\subsubsection{Inclusion Criteria}

- $\quad$ Subjects with aged group 20 to 60

- $\quad$ Both men and women

- $\quad$ Subjects with good cognition

\subsubsection{Exclusion Criteria}

- $\quad$ Subjects who are using oriented app and recognise app

- $\quad$ Subjects with any visual deficits

- Subjects with stroke ,Alzheimer's disease,

- $\quad$ Subjects unable to provide informed consent

- Uncooperative Subjects

\subsection{Outcome measures}

- Response time was be taken from a recognise application; Display resolution , brightness and muted all other notification.

- Here response time is defined as a time taken to response displayed image

- Concurrent validity of the mobile tablet was good to excellent for hand judments (ICC3, $1=0.836$ for RT; ICC $=0.909$ for accuracy), ${ }^{[14]}$

- Test-retest reliability of the mobile tablet was good to excellent (ICC $=0.824$ for accuracy; $\mathrm{ICC}=0.903$ for RT). ${ }^{[14]}$

- Performance measure on the LRDT(response time and accuracy)

- Mean response time for LRDT

- Proportion of correct response will expressed as a percentage.

\subsection{Procedures}

The ethical clearance was obtained from the ethical board of the Oxford ethical board committee. 279 participants were selected for the study on the basis of inclusion and exclusion criteria. A selected apartment around Bangalore and physiotherapy clinics across Bangalore was approached for conducting the study. Permission for conducting the study was obtained from the respective centers.

Participants selected for the study is from age group from age 20 to 60 both gender. Participants was randomly divided into eight groups by stratified randomization The baseline characteristics of gender male and female and age category that is 20-30,31-40,41-50,51-60 .Both male and female age category are formed in order to set normative data. This type of randomization is called Stratified Block Randomization. When we explain and see the participants are interested to take part in our research than Verifying a participants and the participant will be explained about the purpose of the research verbally in the language which they will follow. The information sheet about the study and the consent form should be given to each subject for approval before the study

Pre Test Evaluation

Age -20-60

MMSC score

VAS Score if pain is present

Recent injuries

Medical history

Get the signature of both participants and witness fill the form participant who fit in our inclusion criteria and will to take part in our study were explain the test procedure and test was done.

\subsubsection{Test procedure}

- Participants were in sitting/standing comfortable position. There were asked to be relaxed and concentrate on the task which is perform on tablet. Test was done by using Recognise Android Application on Tablet 10inch.The charge on tablet ,mute all other notifications and brightness were to be checked before performing a test

- 30 random hand images of both left and right side is shown by the Recognise hand app to the participant and ask them to correctly recognize and mark the tick either left or right. After the test was done response time of both left and right were recorded individually on both response time along with that accuracy of the hand images were also recorded

- The test was followed by shoulder image for same participant. 30 random shoulder images of both left and right side is shown by the Recognise Shoulder App to the participant and ask them to correctly recognize and mark the tick either left or right. After the test was done response time of both left and right were recorded individually on both response time along with that accuracy of the shoulder images were also recorded

- The test was followed by foot image for same participant. 30 random foot images of both left and right side is shown by the Recognise Foot App to the participant and ask them to correctly recognize and mark the tick either left or right. After the test was done response time of both left and right were recorded individually on both response time along with that accuracy of the foot images were also recorded

- The test was followed by knee image for same participant. 30 random knee images of both left and right side is shown by the Recognise Knee App to the participant and ask them to correctly recognize and mark the tick either left or right. After the test was done response time of both left and right were recorded individually on both response time along with that accuracy of the knee images were also recorded

- This recognise application gives proper response time in it result section so from that we can take the response time for further calculation

\subsection{Statistical Analysis}

A sample of 279 participants, between 20 to 40 years of age, was selected for the study. Descriptive analysis has been carried out in this present study. In descriptive statistics all categorical variables are presented with frequency, percentage and graphic representation. The quantitative variables are presented on Mean \pm Standard Deviation (SD) [Min-Max].

\subsubsection{Arithmetic Mean}




$$
\bar{x}=\frac{\sum x}{n}
$$

Where

$\mathrm{X}=$ Arithmetic mean,

$\sum \mathrm{xi}=$ sum of all variables,

$\mathrm{n}=$ number of variables.

$$
\sigma=\sqrt{\frac{\sum(X-\bar{X})^{2}}{n-1}}
$$

\subsubsection{Standard Deviation (S.D)}

\section{Where,}

$\mathrm{X}=$ sum of all variables,

$\mathrm{XI}=$ arithmetic mean

$\mathrm{n}=$ number of variables.

\subsubsection{Statistical software}

The statistical software namely SPSS v.23 was used for the analysis of the data and Microsoft word and Excel have been used to generate graphs, tables etc.

\section{Results and Discussion}

The baseline characteristics age and gender wise results was calculated .The normative response time and accuracy for hand image is $2.43 \mathrm{sec}$ with accuracy of $78 \%$. The normative response time and accuracy for shoulder image is $1.90 \mathrm{sec}$ with accuracy of $83.9 \%$. The normative response time and accuracy for foot image is $1.90 \mathrm{sec}$ with accuracy of $87.9 \%$. The normative response time and accuracy for knee image is 2.95 sec with accuracy of $70.5 \%$.

In group (Male age group 20-30) the normative data for hand images we got $2.52 \pm 1.2 \mathrm{sec}$ for left hand image and $2.52 \pm 1$.3sec for right hand image with accuracy of $84 \pm 14$ and $84 \pm 12$ respectively. In group (Male age group 31-40) the normative data for hand images we got $2.43 \pm 1.3 \mathrm{sec}$ for left hand image and $2.88 \pm 1.3 \mathrm{sec}$ for right hand image with accuracy of $78 \pm 18$ and $86 \pm 14$ respectively. In group (Male age group 41-50) the normative data for hand images we got $2.68 \pm 1.3 \mathrm{sec}$ for left hand image and $2.63 \pm 1.4 \mathrm{sec}$ for right hand image with accuracy of $82 \pm 15$ and $83 \pm 13$ respectively. In group (Male age group 51-60) the normative data for hand images we got $2.62 \pm 1.3 \mathrm{sec}$ for left hand image and $2.65 \pm 1.2$ sec for right hand image with accuracy of $74 \pm 17$ and $75 \pm 15$ respectively.

In group (Female age group 20-30) the normative data for hand images we got $2.12 \pm 0.99 \mathrm{sec}$ for left hand image and $2.16 \pm 0.91 \mathrm{sec}$ for right hand image with accuracy of $82 \pm 11$ and $85 \pm 13$ respectively. In group (Female age group 31-40) the normative data for hand images we got $2.07 \pm 1.03 \mathrm{sec}$ for left hand image and $2.21 \pm 0.95 \mathrm{sec}$ for right hand image with accuracy of $74 \pm 15$ and $75 \pm 12$ respectively. In group (Female age group 41-50) the normative data for hand images we got $2.42 \pm 1.16 \mathrm{sec}$ for left hand image and $2.45 \pm 1.14 \mathrm{sec}$ for right hand image with accuracy of $74 \pm 16$ and $76 \pm 13$ respectively. In group (Female age group 51-60) the normative data for hand images we got $2.33 \pm 1.14$ sec for left hand image and $2.3 \pm 1$ sec for right hand image with accuracy of $71 \pm 15$ and $76 \pm 14$ respectively.

In group (Male age group 20-30) the normative data for shoulder images we got $1.74 \pm 0.68 \mathrm{sec}$ for left shoulder image and $1.77 \pm 0.80$ sec for right shoulder image with accuracy of
$91 \pm 11$ and $90 \pm 10$ respectively. In group (Male age group 3140) the normative data for shoulder images we got $1.95 \pm 1.2$ sec for left shoulder image and $1.96 \pm 0.9 \mathrm{sec}$ for right shoulder image with accuracy of $90 \pm 14$ and $87 \pm 10$ respectively. In group (Male age group 41-50) the normative data for shoulder images we got $2.11 \pm 1$ sec for left shoulder image and $2.10 \pm 1$ sec for right shoulder image with accuracy of $85 \pm 13$ and $87 \pm 10$ respectively. In group (Male age group 51-60) the normative data for shoulder images we got $1.98 \pm 1 \mathrm{sec}$ for left shoulder image and $2.02 \pm 0.9$ sec for right shoulder image with accuracy of $77 \pm 19$ and $79 \pm 19$ respectively.

In group (Female age group 20-30) the normative data for shoulder images we got $1.69 \pm 0.5 \mathrm{sec}$ for left shoulder image and $1.93 \pm 0.78 \mathrm{sec}$ for right shoulder image with accuracy of $90 \pm 10$ and $90 \pm 11$ respectively. In group (Female age group 31-40) the normative data for shoulder images we got $1.71 \pm 1.01 \mathrm{sec}$ for left shoulder image and $1.82 \pm 0.85 \mathrm{sec}$ for right shoulder image with accuracy of $83 \pm 15$ and $79 \pm 17$ respectively. In group (Female age group 41-50) the normative data for shoulder images we got $1.91 \pm 0.81 \mathrm{sec}$ for left shoulder image and $1.82 \pm 0.8 \mathrm{sec}$ for right shoulder image with accuracy of $84 \pm 14$ and $80 \pm 17$ respectively. In group (Female age group 51-60) the normative data for shoulder images we got $1.92 \pm 0.9 \mathrm{sec}$ for left shoulder image and $2.04 \pm 0.72$ sec for right shoulder image with accuracy of $75 \pm 19$ and $76 \pm 18$ respectively.

In group (Male age group 20-30) the normative data for foot images we got $1.8 \pm 0.6 \mathrm{sec}$ for left foot image and $1.9 \pm 0.74 \mathrm{sec}$ for right foot image with accuracy of $89 \pm 12$ and $92 \pm 10$ respectively. In group (Male age group 31-40) the normative data for foot images we got $1.8 \pm 0.77$ sec for left foot image and $1.97 \pm 1.01 \mathrm{sec}$ for right foot image with accuracy of $87 \pm 11$ and $88 \pm 12$ respectively. In group (Male age group 4150 ) the normative data for foot images we got $2.07 \pm 1.1 \mathrm{sec}$ for left foot image and $2 \pm 0.9$ sec for right foot image with accuracy of $86 \pm 14$ and $87 \pm 13$ respectively. In group (Male age group 51-60) the normative data for foot images we got $2.22 \pm 1.2 \mathrm{sec}$ for left foot image and $2.05 \pm 0.96 \mathrm{sec}$ for right foot image with accuracy of $87 \pm 16$ and $89 \pm 14$ respectively. In group (Female age group 20-30) the normative data for foot images we got $1.74 \pm 0.66 \mathrm{sec}$ for left foot image and $1.89 \pm 0.76$ sec for right foot image with accuracy of $89 \pm 13$ and $92 \pm 9$ respectively. In group (Female age group 31-40) the normative data for foot images we got $1.94 \pm 0.72 \mathrm{sec}$ for left foot image and $1.72 \pm 0.74 \mathrm{sec}$ for right foot image with accuracy of $86 \pm 15$ and $89 \pm 14$ respectively. In group (Female age group 41-50) the normative data for foot images we got $1.94 \pm 0.72 \mathrm{sec}$ for left foot image and $1.72 \pm 0.74 \mathrm{sec}$ for right foot image with accuracy of $86 \pm 15$ and $89 \pm 14$ respectively. In group (Female age group 51-60) the normative data for foot images we got $1.95 \pm 0.64 \mathrm{sec}$ for left foot image and $1.82 \pm 0.62 \mathrm{sec}$ for right foot image with accuracy of $84 \pm 20$ and $86 \pm 19$ respectively.

In group (Male age group 20-30) the normative data for knee images we got $2.9 \pm 1.09$ sec for left knee image and $2.9 \pm 1.08 \mathrm{sec}$ for right knee image with accuracy of $69 \pm 14$ and $69 \pm 15$ respectively. In group (Male age group 31-40) the normative data for knee images we got $3.2 \pm 1.3 \mathrm{sec}$ for left knee image and $2.66 \pm 0.9 \mathrm{sec}$ for right knee image with accuracy of $72 \pm 12$ and $68 \pm 17$ respectively. In group (Male age group 41-50) the normative data for knee images we got $2.8 \pm 1.3 \mathrm{sec}$ for left knee image and $2.77 \pm 1$.3sec for right knee image with accuracy of $74 \pm 14$ and $72 \pm 14$ respectively. In group (Male age group 51-60) the normative data for knee images we got $3.2 \pm 1.6$ sec for left knee image and 
$3.04 \pm 1$.2sec for right knee image with accuracy of $71 \pm 15$ and $76 \pm 15$ respectively.

In group (Female age group 20-30) the normative data for knee images we got $2.66 \pm 1.10 \mathrm{sec}$ for left foot image and $2.88 \pm 1.15$ sec for right knee image with accuracy of $71 \pm 14$ and $76 \pm 15$ respectively. In group (Female age group 31-40) the normative data for knee images we got $2.92 \pm 1.6 \mathrm{sec}$ for left knee image and $3.02 \pm 1.49$ sec for right knee image with accuracy of $68 \pm 11$ and $72 \pm 15$ respectively. In group (Female age group 41-50) the normative data for knee images we got $2.75 \pm 1.48$ sec for left knee image and $3 \pm 1.5$ sec for right knee image with accuracy of $67 \pm 15$ and $69 \pm 14$ respectively. In group (Female age group 51-60) the normative data for knee images we got $3.10 \pm 1.74$ sec for left knee image and $3.47 \pm 1.75$ sec for right knee image with accuracy of $67 \pm 14$ and $68 \pm 15$ respectively.

\subsection{Tables and Figures}

Table 1: Baseline Characteristics of Participants

\begin{tabular}{|c|c|c|}
\hline Baseline characteristics & $\mathbf{N}$ & $\%$ \\
\hline \multicolumn{2}{|c|}{ Gender - } & Male \\
\hline Age & 136 & $48 \%$ \\
\hline $20-30$ & 59 & $43 \%$ \\
\hline $31-40$ & 18 & $13 \%$ \\
\hline $41-50$ & 26 & $19 \%$ \\
\hline $51-60$ & 33 & $24 \%$ \\
\hline Age & Female \\
\hline 20-30 & 143 & $52 \%$ \\
\hline 31-40 & 45 & $32 \%$ \\
\hline 41-50 & 37 & $25 \%$ \\
\hline 51-60 & 27 & $18 \%$ \\
\hline Result for all participants & Response & Accuracy \\
\hline 1. Hand Image & 234 & $(\%)$ \\
\hline 2. Shoulder Image & 1.90 & $78 \%$ \\
\hline 3. Foot Image & 1.90 & $83.9 \%$ \\
\hline 4. Knee Image & 2.95 & $87.9 \%$ \\
\hline
\end{tabular}

Table: 1 shows the mean values and standard deviation of main variables at the baseline for all participants. The gender of the participants in each group is also presented in Fig. 1 and Fig. 2. Three subjects follow up was lost in between the study due to different reason mentioned in the Fig No other adverse events were reported by the participants.

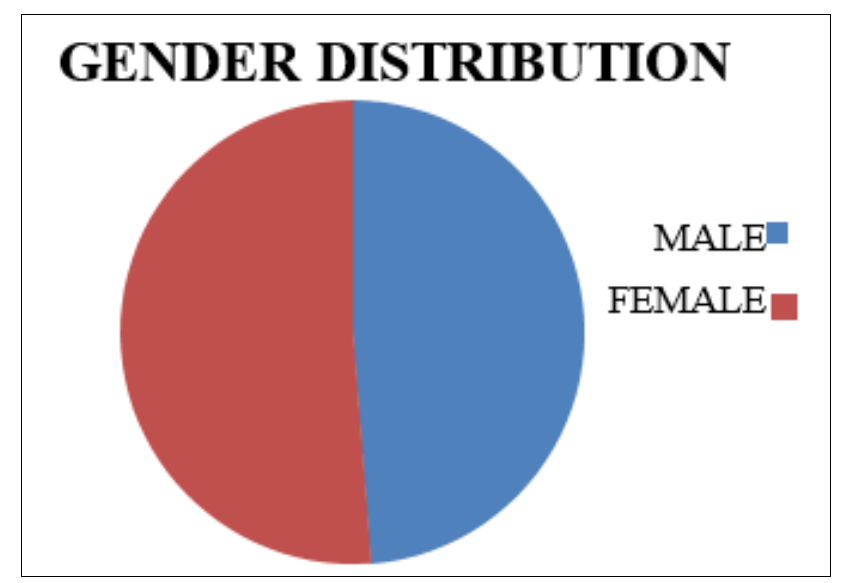

Fig 1: Gender distribution Pie Chart

The above Fig 1 shows gender distribution who has participant in left right judgment task. The total number of male participant are 136 and total number of female participant are 143

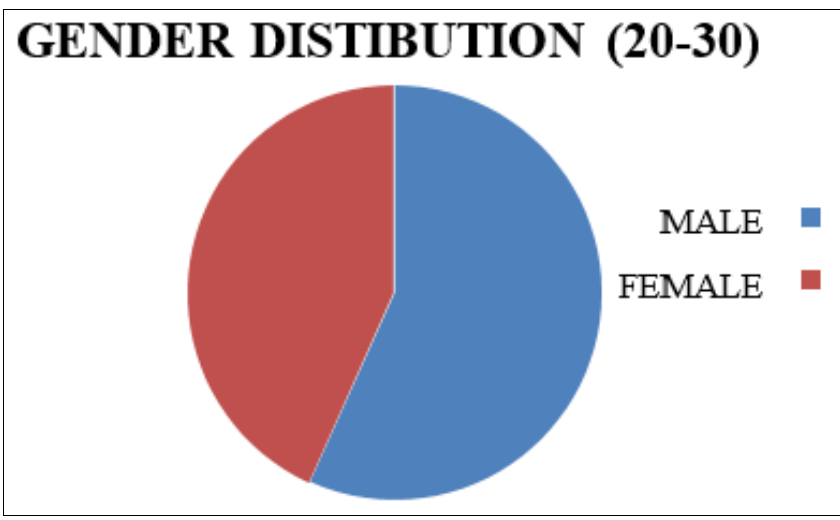

Fig 2: Gender distribution in age group 20-30 Pie Chart

The number of male participants are 59 and female are 45 .

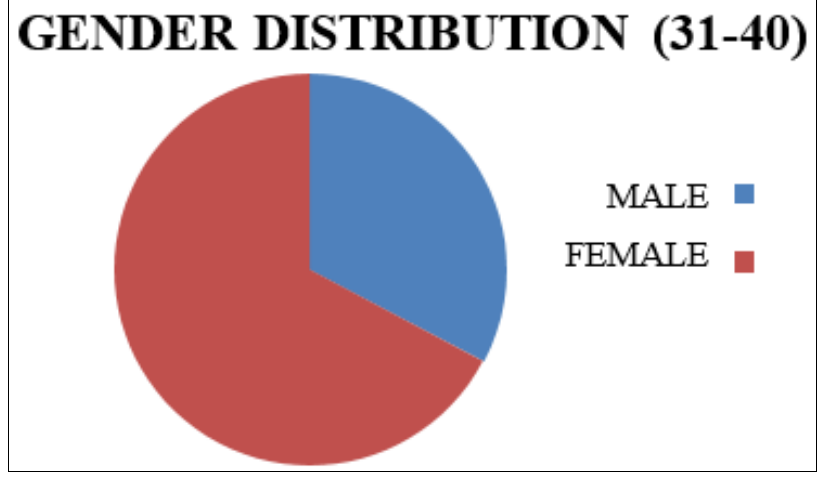

Fig 3: Gender distribution in age group 31-40

The number of male participant are 18 and female participant are 39.

\section{GENDER DISTRIBUTION (41-50)}

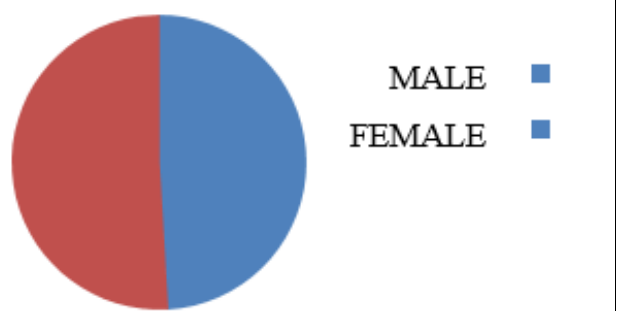

Fig 4: Gender distribution in age group 41-50

The number of male participant are 26 and female participant are 27.

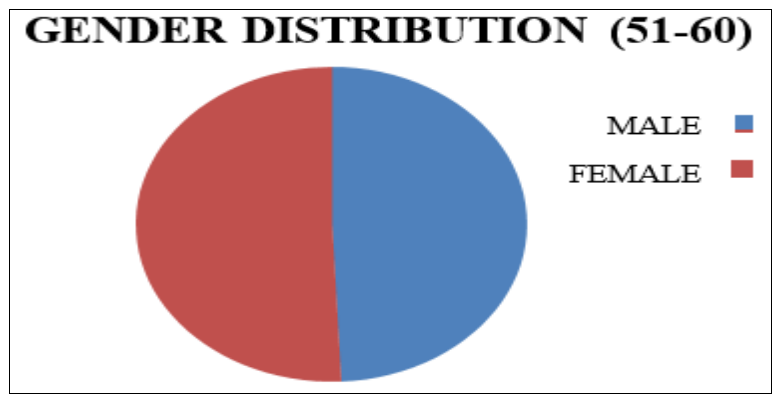

Fig 5: Gender distribution in age group 51-60

The number of male participant are 26 and female participant 
are 27.

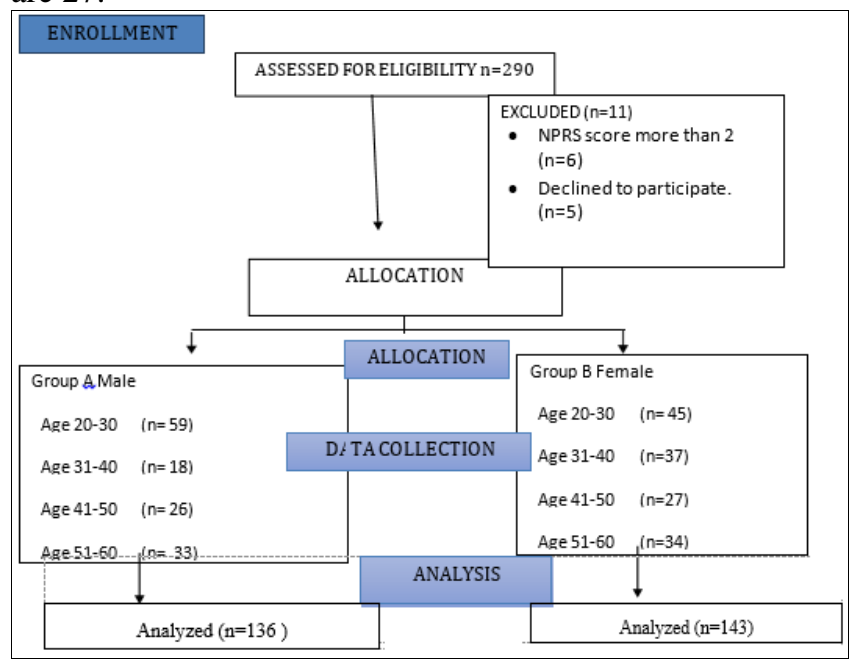

Table 2: Comparison of response time and accuracy of hand image in different age group in male population

\begin{tabular}{|c|c|c|c|c|}
\hline \multirow{3}{*}{$\begin{array}{c}\text { Male Age } \\
\text { (years) }\end{array}$} & \multicolumn{4}{|c|}{ Recognize Hand Image } \\
\hline & \multicolumn{2}{|c|}{$\begin{array}{c}\text { Response } \\
\text { time(sec)(Mean } \pm \text { SD) }\end{array}$} & \multicolumn{2}{|c|}{$\operatorname{Accuracy}(\%)($ Mean \pm SD $)$} \\
\hline & Left image & Right image & Left image & Righ \\
\hline $20-30$ & 1.2 & 1.3 & $84 \pm 14$ & \\
\hline $31-40$ & $2.45 \pm 1.3$ & $2.88 \pm 1.5$ & $78 \pm 18$ & $86 \pm 14$ \\
\hline $41-50$ & $2.68 \pm 1.3$ & $2.63 \pm 1.4$ & $82 \pm 15$ & $83 \pm 13$ \\
\hline $51-60$ & $2.62 \pm 1.3$ & $2.65 \pm 1.2$ & $74 \pm 17$ & $75 \pm 15$ \\
\hline
\end{tabular}

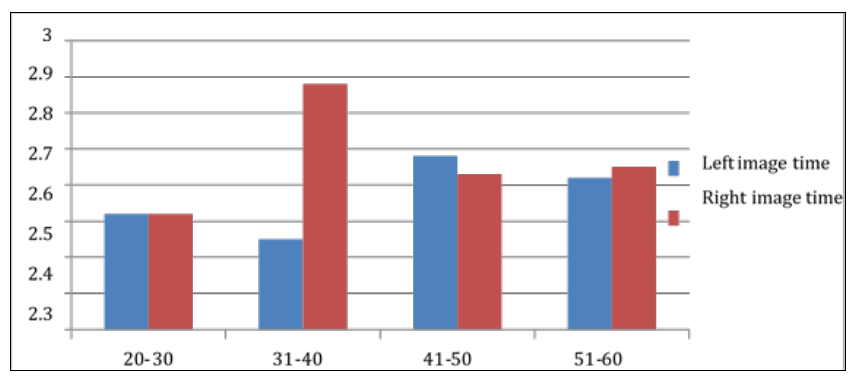

Fig 7: Both left right performance express as response time in sec of hand image in all four age category

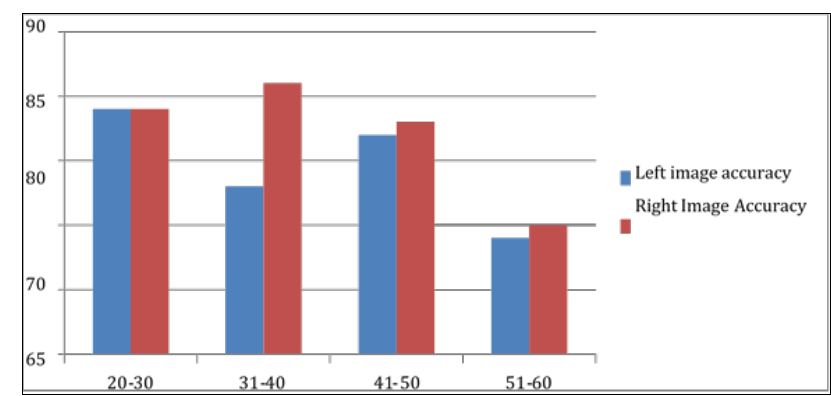

Fig 8: Both left right performance express in accuracy of hand image in all four age Category

Table 3: Comparison of response time and accuracy of hand image in different age group in female population

\begin{tabular}{|c|c|c|c|c|}
\hline \multirow{3}{*}{$\begin{array}{c}\text { Female Age } \\
\text { (years) }\end{array}$} & \multicolumn{4}{|c|}{ Recognize Hand Image } \\
\hline & \multicolumn{2}{|c|}{$\begin{array}{c}\text { Response time(sec) } \\
\text { (Mean } \pm \text { SD) }\end{array}$} & \multicolumn{2}{|c|}{ Accuracy $(\%)($ Mean \pm SD } \\
\hline & \begin{tabular}{|l} 
Left image \\
\end{tabular} & Right image & Left image & Right image \\
\hline $20-30$ & $2.12 \pm 0.99$ & $2.16 \pm 0.91$ & $82 \pm 11$ & $85 \pm 13$ \\
\hline $31-40$ & $2.07 \pm 1.03$ & $2.21 \pm 0.95$ & $74 \pm 15$ & $75 \pm 12$ \\
\hline $41-50$ & $2.42 \pm 1.16$ & $2.45 \pm 1.14$ & $74 \pm 16$ & $76 \pm 13$ \\
\hline $51-60$ & $2.33 \pm 1.14$ & $2.3 \pm 1$ & $71 \pm 15$ & $76 \pm 14$ \\
\hline
\end{tabular}

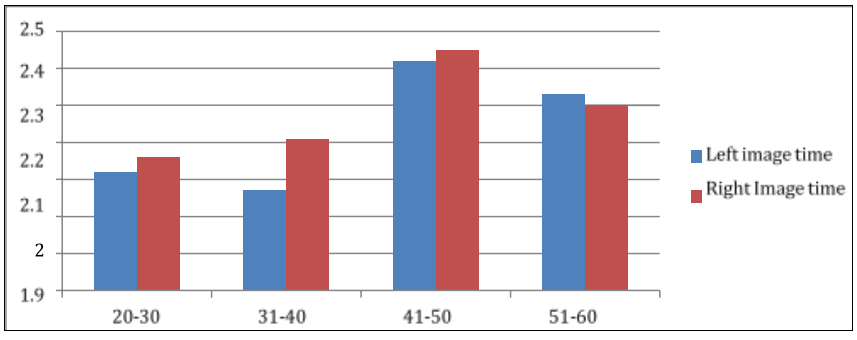

Fig 9: Both left right performance express as response time in sec of hand image in all four age category

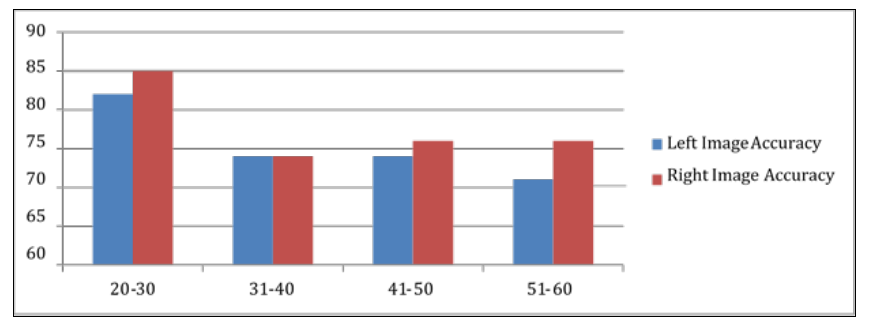

Fig 10: Both left right performance express in accuracy of hand image in all four age catego

Table 4: Comparison of response time and accuracy of shoulder image in different age group in male population

\begin{tabular}{|c|c|c|c|c|}
\hline \multirow{2}{*}{$\begin{array}{c}\text { Male Age } \\
\text { (years) }\end{array}$} & \multicolumn{4}{|c|}{\begin{tabular}{c} 
Recognize Shoulder Image \\
\cline { 2 - 5 }
\end{tabular}} \\
\cline { 2 - 5 } (Meanse time(sec) \\
\cline { 2 - 5 } & Left image & Right image & Left image & Right image \\
\hline $20-30$ & $1.74 \pm 0.68$ & $1.77 \pm 0.80$ & $91 \pm 11$ & $90 \pm 10$ \\
\hline $31-40$ & $1.95 \pm 1.2$ & $1.96 \pm 0.9$ & $90 \pm 14$ & $87 \pm 10$ \\
\hline $41-50$ & $2.11 \pm 1$ & $2.10 \pm 1$ & $85 \pm 13$ & $87 \pm 10$ \\
\hline $51-60$ & $1.98 \pm 1$ & $2.02 \pm 0.9$ & $77 \pm 19$ & $79 \pm 19$ \\
\hline
\end{tabular}

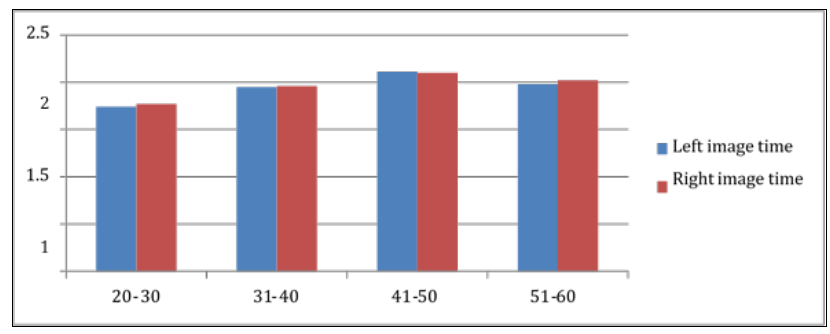

Fig 11: Both left right performance express as response time in sec of shoulder image in all four age category

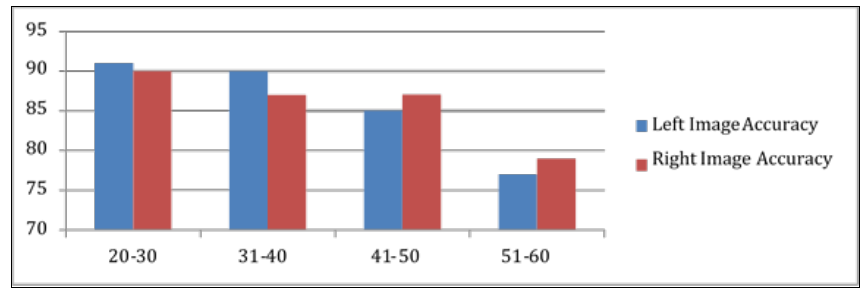

Fig 12: Both left right performance express in accuracy of hand image in all four age category

Table 5: Comparison of response time and accuracy of Shoulder image in different age group in female population

\begin{tabular}{|c|c|c|c|c|}
\hline \multirow{2}{*}{$\begin{array}{c}\text { Female Age } \\
\text { (years) }\end{array}$} & \multicolumn{4}{|c|}{ Recognize Shoulder Image } \\
\cline { 2 - 5 } & $\begin{array}{c}\text { Response } \\
\text { time(sec)(Mean } \pm \text { SD) }\end{array}$ & \multicolumn{2}{c|}{ Accuracy(\%)(Mean \pm SD) } \\
\cline { 2 - 5 } & Left image & Right image & Left image & Right image \\
\hline $20-30$ & $1.69 \pm 0.5$ & $1.93 \pm 0.78$ & $90 \pm 10$ & $90 \pm 11$ \\
\hline $31-40$ & $1.71 \pm 1.01$ & $1.82 \pm 0.84$ & $83 \pm 15$ & $79 \pm 17$ \\
\hline $41-50$ & $1.91 \pm 0.81$ & $1.82 \pm 0.8$ & $84 \pm 14$ & $80 \pm 17$ \\
\hline $51-60$ & $1.92 \pm 0.9$ & $2.04 \pm 0.72$ & $75 \pm 19$ & $76 \pm 18$ \\
\hline
\end{tabular}




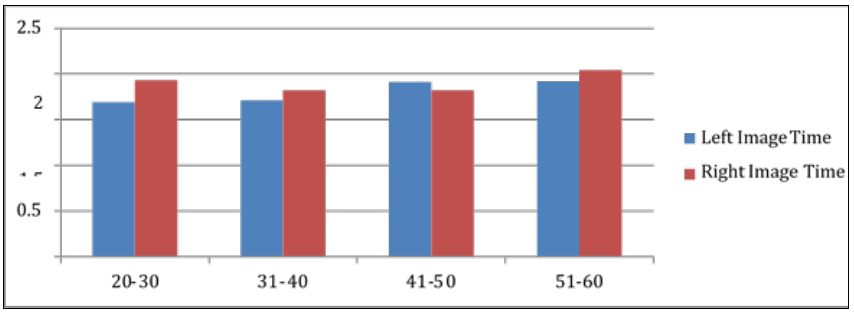

Fig 13: Both left right performance express as response time in sec of shoulder image in all four age category

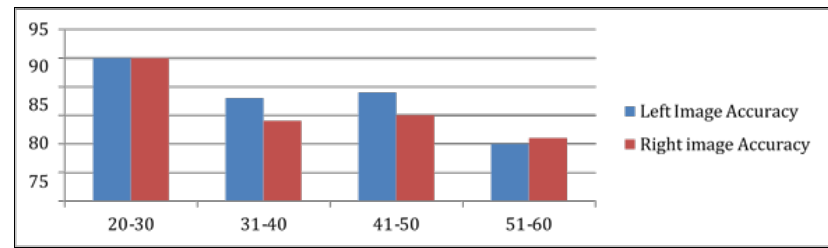

Fig 14: Both left right performance express in accuracy of shoulder image in all four age category

Table 6: Comparison of response time and accuracy of foot image in different age group in male population

\begin{tabular}{|c|c|c|c|c|}
\hline \multirow{3}{*}{$\begin{array}{c}\text { Male Age } \\
\text { (years) }\end{array}$} & \multicolumn{4}{|c|}{ Recognize Foot Image } \\
\hline & \multicolumn{2}{|c|}{$\begin{array}{l}\text { Response time(sec) } \\
\text { (Mean } \pm \text { SD) }\end{array}$} & \multicolumn{2}{|c|}{$\operatorname{Accuracy}(\%)($ Mean \pm SD $)$} \\
\hline & Left image & Right image & Left image & Right image \\
\hline $20-30$ & $1.8 \pm 0.6$ & $1.9 \pm 0.74$ & $89 \pm 12$ & $92 \pm 10$ \\
\hline $31-40$ & $1.8 \pm 0.77$ & $1.97 \pm 1.01$ & $87 \pm 11$ & $88 \pm 12$ \\
\hline $41-50$ & $2.07 \pm 1.1$ & $2 \pm 0.9$ & $86 \pm 14$ & $87 \pm 13$ \\
\hline $51-60$ & $2.22 \pm 1.2$ & $2.05 \pm 0.96$ & $87 \pm 16$ & $89 \pm 14$ \\
\hline \\
\hline \multicolumn{5}{|l|}{$2.5^{-}$} \\
\hline 2 & & & & - Left image Time \\
\hline 1.5 & & & & - Right Image time \\
\hline 20 & $31-40$ & $41-50$ & $51-60$ & \\
\hline
\end{tabular}

Fig 15: Both left right performance express as response time in sec of foot image in all four age category

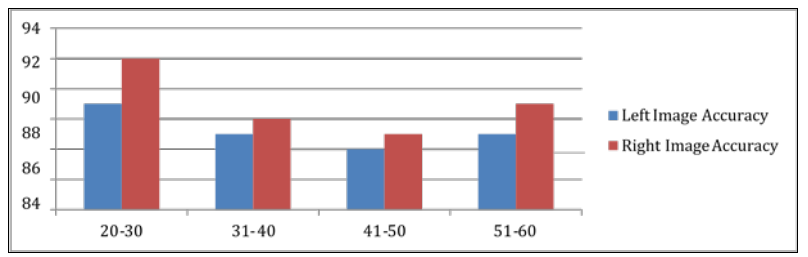

Fig 16: Both left right performance express in accuracy of foot image in all four age category

Table 7: Comparison of response time and accuracy of foot image in different age group in female population

\begin{tabular}{|c|c|c|c|c|}
\hline \multirow{3}{*}{$\begin{array}{c}\text { Female Age } \\
\text { (years) }\end{array}$} & \multicolumn{4}{|c|}{ Recognize Foot Image } \\
\hline & \multicolumn{2}{|c|}{$\begin{array}{c}\text { Response time(sec) } \\
\text { (Mean } \pm \text { SD) }\end{array}$} & \multicolumn{2}{|c|}{ Accuracy $(\%)($ Mean $\pm S D)$} \\
\hline & Left image & Right image & Left image & Right ims \\
\hline & $174+$ & & & \\
\hline & 0 & & & \\
\hline $41-50$ & $1.94 \pm 0.72$ & $1.72 \pm 0.74$ & & $89 \pm 14$ \\
\hline $51-60$ & $1.95 \pm 0.64$ & $1.82 \pm 0.62$ & $84 \pm 20$ & $86 \pm 19$ \\
\hline
\end{tabular}

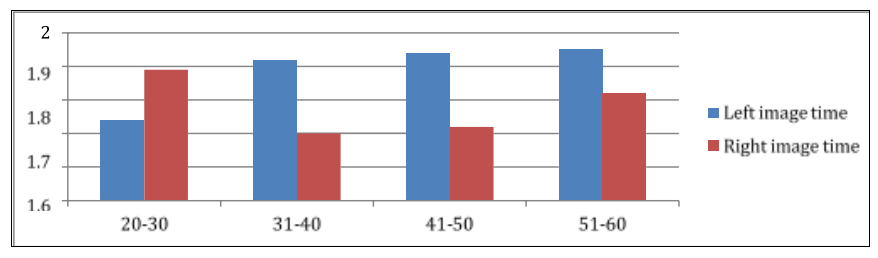

Fig 17: Both left right performance express as response time in sec of foot image in all four age category

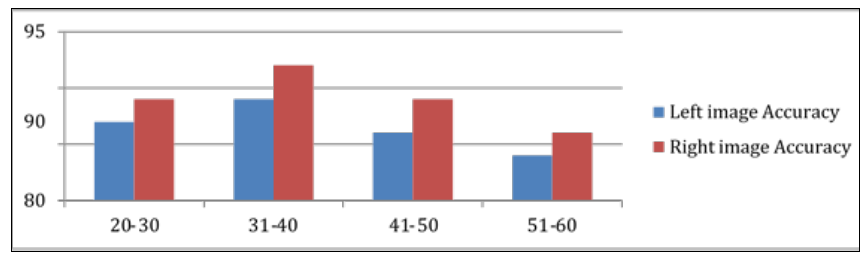

Fig 18: Both left right performance express in accuracy of foot image in all four age category

Table 8: Comparison of response time and accuracy of Knee image in different age group in male population

\begin{tabular}{|c|c|c|c|c|}
\hline \multirow{2}{*}{$\begin{array}{c}\text { Male Age } \\
\text { (years) }\end{array}$} & \multicolumn{4}{|c|}{ Recognize Knee Image } \\
\cline { 2 - 5 } & $\begin{array}{c}\text { Response } \\
\text { time(sec)(Mean } \pm \text { SD) }\end{array}$ & \multicolumn{2}{c|}{ Accuracy(\%)(Mean \pm SD) } \\
\cline { 2 - 5 } & Left image & Right image & Left image & Right image \\
\hline $20-30$ & $2.9 \pm 1.09$ & $2.9 \pm 1.08$ & $69 \pm 14$ & $69 \pm 15$ \\
\hline $31-40$ & $3.2 \pm 1.3$ & $2.66 \pm 0.9$ & $72 \pm 12$ & $68 \pm 17$ \\
\hline $41-50$ & $2.8 \pm 1.3$ & $2.77 \pm 1.3$ & $74 \pm 14$ & $72 \pm 14$ \\
\hline $51-60$ & $3.2 \pm 1.6$ & $3.04 \pm 1.2$ & $71 \pm 15$ & $76 \pm 15$ \\
\hline
\end{tabular}

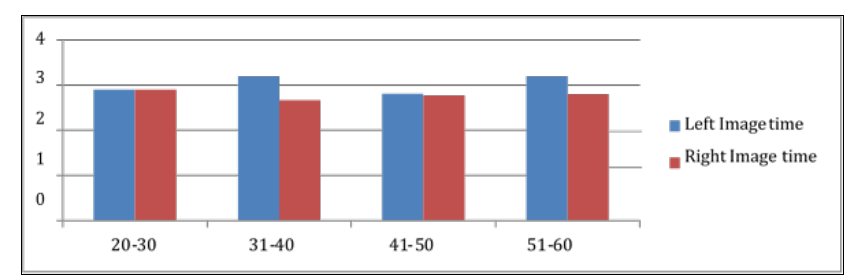

Fig 19: Both left right performance express as response time in sec of knee image in all four age category

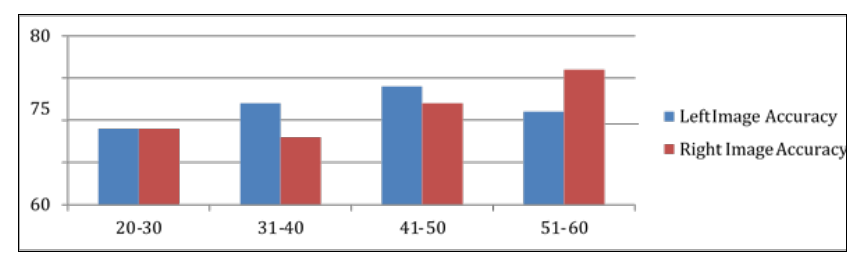

Fig 20: Both left right performance express in accuracy of knee image in all four age category

Table 9: Comparison of response time and accuracy of Knee image in different age group in female population

\begin{tabular}{|c|c|c|c|c|}
\hline \multirow{3}{*}{$\begin{array}{c}\text { Female Age } \\
\text { (years) }\end{array}$} & \multicolumn{4}{|c|}{ Recognize Knee Image } \\
\hline & \multicolumn{2}{|c|}{$\begin{array}{c}\text { Response } \\
\text { time(sec)(Mean } \pm \text { SD) }\end{array}$} & \multicolumn{2}{|c|}{ Accuracy $\%($ Mean \pm SD $)$} \\
\hline & Left image & Right i & Lef & $\begin{array}{l}\text { Right } \\
\text { image }\end{array}$ \\
\hline $20-30$ & $2.66 \pm 1.10$ & $2.88 \pm 1.15$ & $71 \pm 14$ & $76 \pm 15$ \\
\hline $31-40$ & $2.92 \pm 1.6$ & $3.02 \pm 1.49$ & $68 \pm 11$ & $72 \pm 15$ \\
\hline $41-50$ & $2.75 \pm 1.48$ & $3 \pm 1.5$ & $67 \pm 15$ & $69 \pm 13$ \\
\hline $51-60$ & $3.10 \pm 1.74$ & $3.47 \pm 1.75$ & $67 \pm 14$ & $68 \pm 15$ \\
\hline
\end{tabular}




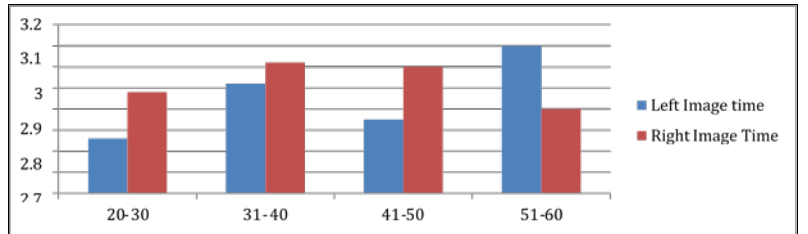

Fig 21: Both left right performance express as response time in sec of knee image in all four age category

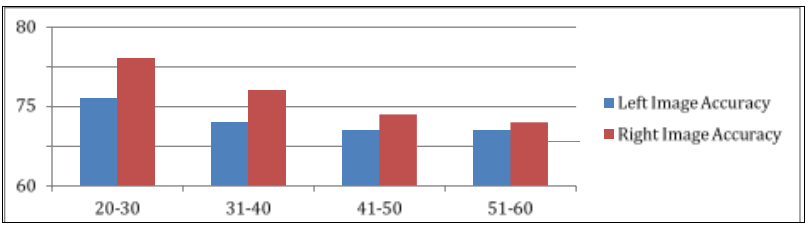

Fig 22: Both left right performance express in accuracy of knee image in all four age category

\subsection{Discussion}

Previous research shows that people who are in pain often lose their ability left or right image of their painful body parts. When using GMI this ability appears to be important for the normal recovery from the pain. As we know that the brain is plastic and changeable if given the right training for long enough. It is also possible to improve the ability (speed and accuracy) to discriminate between left and right body parts and movement ${ }^{[14]}$.

This present study was designed to set a normal left right response time of body parts i.e hand, shoulder, foot and knee. The main findings of the study give us normative data of this body parts in different age category in context to the Indian population. The purpose to set this normative data for Indian Population is because pain is a learned response which varies because of the behavior to the pain, day to day lifestyle and belief towards the pain. The normative data we set from this study can be compared with left right discrimination that is response time and accuracy on various chronic pain like phantom pain syndrome, complex regional pain syndrome, low back pain, painful arthritis, neck pain condition which helps to monitor.

The previous research suggestion for normal response to left right discrimination test had a speed of $2 \mathrm{sec}+/-0.5 \mathrm{sec}$ for hand and feet image where as there were no study for normative data for others body parts such as knee and shoulder. And even they suggest accuracy and response times should be reasonably equal for the left and right image of different body parts.

Here in the present study we have given response time and accuracy for both left and right body parts image separately. And also include the study on knee and shoulder image discrimination ability and accuracy. Our study suggests that there is slightly change in accuracy and response time for the left and right image of different body parts. Even we set the normative data for both gender separately. We have also set normative data for different age category that is 20-30, 3140,41-50,51-60.

The previous study found that the accuracy to correctly identifying image is inversely proportional to the response time .Even in this study those participants whose accuracy of identifying image is more they have taken longer response time. Young participants thought it was challenge to complete as soon as possible in hand image and knee image they took shorter response duration and accuracy rate are low where as young participants found easier and took decent time with good accuracy in shoulder and foot image. Whereas mid age and old age performed test on their own pace their result are those who have good accuracy took longer response duration all four image.

A total number of 279 participants were taken part of our study .One study gives response times for the different sub group which was lack in the previous study the sub group include male age group 20-30(n=59) ,male age group 31$40(n=18)$, male age group 41-50(n=26), male age group 5160( $\mathrm{n}=33)$,female age group 20-30(n=45), female age group 31-40(37) ,female age group 41-50(27),female age group (34).

The response time taken to discrimination left right image of hand and knee image takes longer response time than the shoulder and foot image. On that also knee image takes longer response time and accuracy to correctly identifying knee image are less compared to the other image. As our study also gives the response and accuracy of both left and right image of all four body parts.

Our study also present data in both gender we have found out that in some age category women took longer response time and the accuracy to identifying left right image in less in compared to the men. On the knee image woman c41-50 age category the response time of left and right image is 2.75 and 3 sec with accuracy 67 and $68 \%$ respectively. And the response time of left right knee image is $3.10 \mathrm{sec}$ and $3.47 \mathrm{sec}$ with accuracy of average $68 \%$ in women age 51-60. In these category of women, they have OA of the knee though we have not included the participant who has pain but at that point of time we test they didn't have pain and we include them in the study .this could be the possible reason that these age category women has taken longer response time with less accuracy.

\subsection{Limitations of the Study}

- Lack of interest of the participants as this study doesn't give the immediate benefits.

- As this study is conducted during COVID pandemic and most of the participants were economical and emotional crisis and had a fear of getting infected that might affect the result of the study.

- Each group result has small sample size.

- Duration of the study can be done longer so more participants can be included in the study

\subsection{Recommendations}

- Large study involving increased number of participants should be employed.

- Study should be done in various part of the India

- Comparative study can be done with subject with chronic pain.

- Further study on age category below 20 and above 60 years old age can be done

\subsection{Clinical Implications}

The implication of the study is that LRD normative value can be used to monitor changes on various chronic pain condition. While conducting a research on LRD in painful condition this data will help to interpret the result.

\section{Conclusions}

Results from statistical analysis done on the data analysis done on the data collected shows we had collected response time and accuracy for different body parts i.e. hand, shoulder, foot, and knee. We had presented the response time and accuracy for age category and gender wise. Our study also 
present data in both genders we have found out that in some age category women took longer response time and the accuracy to identifying left right image in less in compared to the men.

Overall performance was done and compare with healthy participants. If the further left right discrimination research done on subject with affected body parts this research provide additional data and arguments for maintaining activity in context to pain rehabilitation and self-management.

\section{References}

1. Mills SE, Nicolson KP, Smith BH. Chronic pain: a review of its epidemiology and associated factors in population-based studies. British journal of anaesthesia. 2019 Aug 1;123(2):e273-83.

2. Breckenridge JD, Ginn KA, Wallwork SB, McAuley JH. Do people with chronic musculoskeletal pain have impaired motor imagery? A meta-analytical systematic review of the left/right judgment task. The Journal of Pain. 2019 Feb 1;20(2):119-32.

3. Anderson B, Meyster V. Treatment of a Patient With Central Pain Sensitization Using Graded Motor Imagery Principles: A Case Report. Journal of chiropractic medicine. 2018 Dec1;17(4):264-7.

4. Pelletier R, Paquette É, Bourbonnais D, Higgins J, Harris PG, Danino MA. Bilateral sensory and motor as well as cognitive differences between persons with and without musculoskeletal disorders of the wrist and hand. Musculoskeletal Science and Practice. 2019 Dec 1;44:102058.

5. Bowering KJ, O\&\#39;Connell NE, Tabor A, Catley MJ, Leake HB, Moseley GL, Stanton TR. The effects of graded motor imagery and its components on chronic pain: a systematic review and meta-analysis. The Journal of Pain. 2013 Jan 1;14(1):3-13.

6. Ratcliff R. A diffusion model account of response time and accuracy in a brightness discrimination task: Fitting real data and failing to fit fake but plausible data. Psychonomic bulletin \& review. 2002 Jun;9(2):278-91.

7. Guillot, A.; Collet, C. Contribution from neurophysiological and psychological methods to the study of motor imagery. Brain Res. Rev. 2005, 50, 387397

8. Moseley GL. Graded motor imagery for pathologic pain: a randomized controlled trial. Neurology. 2006 Dec 26;67(12):2129-34.

9. Constant M, Mellet E. The Impact of Handedness, Sex, and Cognitive Abilities on Left-Right Discrimination: A Behavioral Study. Frontiers in psychology. 2018 Mar 27;9:405.

10. Gormley GJ, Dempster M, Best R. Right-left discrimination among medical students: questionnaire and psychometric study. Bmj. 2008 Dec 16;337:a2826.

11. McKinley J, Dempster M, Gormley GJ. 'Sorry, I meant the patient\&\#39;s left side': impact of distraction on leftright discrimination. Medical education. 2015 Apr;49(4):427-35.

12. Grewe P, Ohmann HA, Markowitsch HJ, Piefke M. The Bergen left-right discrimination test: practice effects, reliable change indices, and strategic performance in the standard and alternate form with inverted stimuli. Cognitive processing. 2014 May 1;15(2):159-72.

13. Jordan K, Wüstenberg T, Jaspers-Feyer F, Fellbrich A, Peters M. Sex differences in left/right confusion. Cortex. 2006 Jan 1;42(1):69-78.
14. Williams LJ, Braithwaite FA, Leake HB, McDonnell MN, Peto DK, Moseley GL, Hillier SL.Reliability and validity of a mobile tablet for assessing left/right judgements. Musculoskeletal Science and Practice. 2019 Apr 1;40:45-52. 